\title{
MicroRNA-126 is downregulated in thyroid cancer cells, and regulates proliferation, migration and invasion by targeting CXCR4
}

\author{
YAN QIAN $^{1 *}$, XIAOLI WANG ${ }^{2 *}$, ZHANLU LV $^{1}$, CHEN GUO $^{1}$, YONGJIAN YANG ${ }^{3}$, \\ JINLIANG ZHANG ${ }^{1}$ and XIANLIANG WANG ${ }^{1,4}$
}

\begin{abstract}
${ }^{1}$ Department of Environmental Pollution and Health, State Key Laboratory of Environmental Criteria and Risk Assessment, Chinese Research Academy of Environmental Sciences, Beijing 100012; ${ }^{2}$ Laboratory of Virus Pharmacology,

College of Life Science and Bioengineering, Beijing University of Technology, Beijing 102488;

${ }^{3}$ Department of Occupational and Environmental Medicine, School of Public Health, Anhui Medical University, Hefei, Anhui 230032; ${ }^{4}$ Department of Environmental Health Hazard Protection,
\end{abstract} Institute of Environmental Health and Related Product Safety, Chinese Center for Disease Control and Prevention, Beijing 100050, P.R. China

Received June 14, 2015; Accepted April 19, 2016

DOI: $10.3892 / \mathrm{mmr} .2016 .5276$

\begin{abstract}
MicroRNA-126 (miR-126) has previously been reported to be downregulated in various types of cancer; however, at present, there are no studies of miR-126 in human thyroid cancer. The present study aimed to determine the expression and effects of miR-126 on thyroid cancer. The expression levels of miR-126 were detected in human thyroid cancer tissues, matched normal adjacent tissues and human thyroid cancer cell lines using quantitative polymerase chain reaction. In addition, post-transfection of human thyroid cancer cells with miR-126 mimics, cell proliferation, migration and invasion assays, western blot analysis and luciferase assays were conducted. The results demonstrated that miR-126 was downregulated in thyroid cancer tissues and cells. Furthermore, upregulation of miR-126 inhibited cell proliferation, migration and invasion in thyroid cancer cells. The present study also provided evidence suggesting that miR-126 may directly target C-X-C chemokine receptor type 4 (CXCR4) in thyroid cancer. These results indicated that miR-126 may be investigated as a target for the treatment of thyroid cancer.
\end{abstract}

Correspondence to: Professor Xianliang Wang, Department of Environmental Pollution and Health, State Key Laboratory of Environmental Criteria and Risk Assessment, Chinese Research Academy of Environmental Sciences, 8 Dayangfang BeiYuan Road, Chaoyang, Beijing 100012, P.R. China

E-mail: beijing_yanqian@163.com

*Contributed equally

Key words: thyroid cancer, C-X-C chemokine receptor type 4, microRNA-126, metastasis

\section{Introduction}

Thyroid cancer represents the most common endocrine malignancy, and its incidence has continued to rise worldwide over the past few decades (1). The estimated incidence rate for thyroid cancer is $\sim 1.7 \%$ of total cancer diagnoses worldwide, and the mortality rate has improved in China during recent years (2). Thyroid cancer accounts for 5-10\% of cancers in women (3), and is classified into four major histological groups: Papillary thyroid carcinoma (PTC), follicular thyroid carcinoma, poorly differentiated carcinoma and undifferentiated anaplastic carcinoma (4). PTC is the most common type of thyroid cancer and accounts for $\sim 80 \%$ of all thyroid cancers (5). Although the majority of patients with PTC display a good prognosis, patients with locoregional recurrence and distant metastases frequently have a poor clinical prognosis following treatment with standard therapies $(6,7)$. Therefore, understanding the molecular mechanisms underlying the progression of thyroid cancer, and the development of novel targeted therapies are important, in order to improve the prognosis for patients with thyroid cancer.

Recently, aberrant expression of microRNAs (miRNAs) has been demonstrated in various types of human cancer, including thyroid cancer (8). miRNAs belong to a class of non-coding small RNA molecules, $19-25$ nucleotides long (9). miRNAs regulate target mRNA translation and stability by binding to their 3 '-untranslated regions (3'-UTRs) $(10,11)$. Previous studies have suggested that miRNAs have essential roles in biological processes, including cell cycle progression, cell proliferation, migration, invasion, apoptosis, differentiation and development $(12,13)$.

Certain miRNAs may function as tumor suppressor genes or oncogenes in the development of tumors (14). miRNAs can exert tumour-suppressing and tumour-promoting activities, thus indicating that miRNA-targeting therapeutic strategies 
may be promising in the treatment of cancer (15). The identification of miRNA targets is important to understand the function of miRNAs in tumorigenesis and progression, and miRNA have also been suggested as a potential target for cancer therapy.

Downregulation of miR-126 has been verified in various types of cancer (16-19). However, to the best of our knowledge, there are currently no studies regarding miR-126 expression in human thyroid cancer. In the present study, the expression and function of miR-126 was determined in human thyroid cancer. The results demonstrated that miR-126 was downregulated in human thyroid cancer tissues and cell lines. Conversely, upregulation of miR-126 decreased cell proliferation, migration and invasion by directly targeting $\mathrm{C}-\mathrm{X}-\mathrm{C}$ chemokine receptor type 4 (CXCR4). These finding have therapeutic implications and may be exploited for the future treatment of human thyroid cancer.

\section{Materials and methods}

Clinical specimens. The present study was approved by the ethics committee of the Chinese Research Academy of Environmental Sciences' Protection of Human Subjects (Beijing, China). A total of 20 pairs of human PTC tissues and matched normal adjacent tissues (NATs) were collected from patients (9 males and 11 females; age, 27-77 years old) diagnosed with PTC and had undergone surgery at hospitals associated with Anhui Medical University (Anhui, China). Written informed consent was provided by all patients in the present study. Tissues were immediately snap-frozen in liquid nitrogen following surgery and were stored at $-80^{\circ} \mathrm{C}$.

Cell culture. The human PTC cell lines, TPC-1 and HTH83, were purchased from the Shanghai Institute of Biochemistry and Cell Biology (Shanghai, China). TPC-1 and HTH83 cells were cultured in Dulbecco's modified Eagle's medium (DMEM; Gibco; Thermo Fisher Scientific, Inc., Waltham, MA, USA) supplemented with $10 \%$ fetal bovine serum (FBS), $100 \mathrm{IU} / \mathrm{ml}$ penicillin and $100 \mathrm{mg} / \mathrm{ml}$ streptomycin (Gibco; Thermo Fisher Scientific, Inc.) in a $5 \% \mathrm{CO}_{2}$ cell incubator at $37^{\circ} \mathrm{C}$.

RNA isolation and reverse transcription-quantitative polymerase chain reaction $(R T-q P C R)$. PTC tissues and NATs were homogenized, then RNA was isolated from tissues and PCT cells using TRIzol reagent (Invitrogen; Thermo Fisher Scientific, Inc.) according to the manufacturer's protocol. RT was performed using the Reverse Transcription kit (Tiangen Biotech Co., Ltd., Beijing, China). The incubation protocol for RT $70^{\circ} \mathrm{C}$ for $5 \mathrm{~min}, 0^{\circ} \mathrm{C}$ for $2 \mathrm{~min}, 42^{\circ} \mathrm{C}$ for $50 \mathrm{~min}$ and $95^{\circ} \mathrm{C}$ for $5 \mathrm{~min}$. The expression levels of miR-126 were quantified using the All-in-One ${ }^{\mathrm{TM}}$ miRNA qRT-PCR Detection kit (GeneCopoeia, Inc., Rockville, MD, USA) and ABI Prism 7500 Real-Time PCR System (Applied Biosystems; Thermo Fisher Scientific, Inc.). Primers were purchased from Guangzhou RiboBio Co., Ltd. (Guangzhou, China). The reaction system contained $10 \mu 1$ 2XAll-in-One qPCR Mix, $2 \mu 1$ forward primer, $2 \mu \mathrm{l}$ reverse primer, $2 \mu \mathrm{l} \mathrm{cDNA}$ and $4 \mu \mathrm{l}$ double distilled water. The thermocycling conditions of the reaction were as follows: $95^{\circ} \mathrm{C}$ for $10 \mathrm{~min}$; then 40 cycles of $95^{\circ} \mathrm{C}$ for $10 \mathrm{sec}, 55^{\circ} \mathrm{C}$ for
$20 \mathrm{sec}$ and $72^{\circ} \mathrm{C}$ for $10 \mathrm{sec}$. U6 small RNA was used as an internal control with relative RNA levels calculated using the $2^{-\Delta \Delta C q}$ method (20). Each sample was analyzed in triplicate.

Cell transfection. Mature miR-126 mimics, miRNA negative control (NC) mimics and the luciferase reporter plasmid were purchased from Shanghai GenePharma Co., Ltd. (Shanghai, China). TPC-1 and HTH83 cells were seeded onto a 6-well plate and were cultured with antibiotic-free DMEM. Cells were transfected with miR-126 mimics, NC mimics or the luciferase reporter plasmid using Lipofectamine 2000 (Invitrogen; Thermo Fisher Scientific, Inc.) when cell density reached $30-40 \%$, according to the manufacturer's protocols.

Cell proliferation assay. The proliferation of PTC cells was determined using a 3-(4,5-dimethyl-2-thiazoyl)-2,5-diphenyl-2H-tetrazolium bromide (MTT) assay according to the manufacturer's protocol. Cells were seeded onto 96-well plates at a density of $3 \times 10^{3}$ cells/well 24 h post-transfection with miR-126 or NC mimics. At various time points post-transfection, $20 \mu \mathrm{l} \mathrm{MTT}(5 \mathrm{mg} / \mathrm{ml}$; Sigma-Aldrich, St. Louis, MO, USA) solution was added to each well and incubated at $37^{\circ} \mathrm{C}$ for $4 \mathrm{~h}$. Following removal of the MTT solution, the formazan precipitates were dissolved in $200 \mu \mathrm{l}$ dimethyl sulfoxide. The absorbance was measured at $490 \mathrm{~nm}$ using an xMark enzyme-linked immunosorbent assay reader (Bio-Rad Laboratories, Inc., Hercules, CA, USA). All experiments were performed in triplicate. Suppression rate was calculated using the following formula: Suppression rate $=\left(1-\mathrm{OD}_{\mathrm{miR}-126} / \mathrm{OD}_{\mathrm{mi}}\right.$ R-NC) x $100 \%$; where OD refers to optical density.

Cell migration assay. The migration potential of TPC-1 and HTH-83 cells was determined using Transwell chambers with an $8-\mu \mathrm{m}$ pore polycarbonate membrane (Costar; Corning Incorporated, Corning, NY, USA). A total of $5 \times 10^{4}$ cells, transfected with miR-126 or NC mimics, in $200 \mu \mathrm{l}$ DMEM without serum were added to the upper chamber. A total of $0.5 \mathrm{ml}$ DMEM supplemented with $10 \%$ FBS was added to the lower chamber. Following a $12 \mathrm{~h}$ incubation at $37^{\circ} \mathrm{C}$, the TPC-1 and $\mathrm{HTH}-83$ cells that had not migrated through the pores were carefully removed with cotton wool. The inserts were then fixed with $100 \%$ methanol, stained with $0.5 \%$ crystal violet (Beyotime Institute of Biotechnology, Haimen, China) and were counted under an inverted microscope (CKX41; Olympus Corporation, Tokyo, Japan).

Cell invasion assay. The invasion potential of TPC-1 and HTH-83 cells was determined using Transwell chambers with an $8-\mu \mathrm{m}$ pore polycarbonate membrane (Costar) coated with Matrigel (BD Bioscience, San Jose, CA, USA). A total of $5 \times 10^{4}$ cells, transfected with miR-126 or NC mimics, in $200 \mu \mathrm{l}$ DMEM without serum were added to the upper chamber. A total of $0.5 \mathrm{ml}$ DMEM supplemented with $10 \%$ FBS was added to the lower chamber. Following a $24 \mathrm{~h}$ incubation at $37^{\circ} \mathrm{C}$, the TPC-1 and HTH-83 cells that had not invaded through the pores were carefully removed with cotton wool. The inserts were then fixed with $100 \%$ methanol, stained with $0.5 \%$ crystal violet (Beyotime Institute of Biotechnology) and were counted under an inverted microscope (CKX41; Olympus Corporation). 
Western blotting. A total of $72 \mathrm{~h}$ post-transfection, total cellular proteins was extracted from the cells using radioimmunoprecipitation assay lysis buffer (Beyotime Institute of Biotechnology). The protein concentration was measured using the bicinchoninic acid protein assay kit (Beyotime Institute of Biotechnology), according to the manufacturer's protocol. Equal amounts of protein $(20 \mu \mathrm{g})$ were separated by $10 \%$ sodium dodecyl sulfate-polyacrylamide gel electrophoresis, and were then transferred to polyvinylidene difluoride membranes (EMD Millipore, Billerica, MD, USA). The membranes were blocked with 5\% non-fat dry milk for $2 \mathrm{~h}$, and were then incubated overnight at $4^{\circ} \mathrm{C}$ with the primary antibodies, according to the manufacturer's protocols. Subsequently, the membranes were incubated with goat anti-rabbit (1:5,000 dilution; cat. no. sc-2054; Santa Cruz Biotechnology, Inc., Dallas, TX, USA) or goat anti-mouse (1:5,000 dilution; cat. no. sc-2055; Santa Cruz Biotechnology, Inc.) horseradish-peroxidase conjugated antibodies fro $2 \mathrm{~h}$ at room temperature. The primary antibodies used were as follows: Rabbit anti-human CXCR4 (1:1,000 dilution; cat. no. sc-9046; Santa Cruz Biotechnology, Inc.) and mouse anti-human $\beta$-actin (1:1,000 dilution; cat. no. sc-130300; Santa Cruz Biotechnology, Inc.). Blots were visualized using enhanced chemiluminescence reagents (EMD Millipore). $\beta$-actin was used as a loading control. The intensity of the bands was determined with Image Lab software (Bio-Rad Laboratories, Inc.).

Luciferase assay. To determine whether CXCR4 was a direct target of miR-126, a luciferase activity assay was conducted. pMIR-CXCR4-3'UTR wild-type and pMIR-CXCR4-3'UTR mutant plasmids were obtained from GenePharma Co., Ltd. TPC- 1 and HTH- 83 cells were transfected with $0.5 \mu \mathrm{g}$ wild-type or mutant plasmids, and $40 \mathrm{nmol}$ miR-126 or NC mimics in a 12-well plate using Lipofectamine 2000 (Invitrogen; Thermo Fisher Scientific, Inc.). A total of $48 \mathrm{~h}$ post-transfection, firefly and Renilla luciferase activities were measured using the Dual-Luciferase Reporter Assay system (Promega Corporation, Manheim, Germany) with the xMark microplate reader. Firefly luciferase activity was normalized to Renilla luciferase activity. Each sample was analyzed in triplicate.

Statistical analysis. Data are presented as the mean \pm standard deviation and compared using Student's t test and analysis of variance. Results were analyzed using SPSS software (version 19; IBM SPSS, Armonk, NY, USA). P<0.05 was considered to indicate a statistically significant difference.

\section{Results}

miR-126 expression in PTC tissues and cell lines. To detect the expression levels of miR-126 in 20 PTC tissues and matched NATs, RT-qPCR was performed. As presented in Fig. 1A, miR-126 was significantly downregulated in PTC tissues compared with in the matched NATs $(\mathrm{P}=0.011)$. In addition, the expression levels of miR-126 were compared between TPC-1 and HTH83 cell lines, and NATs. As presented in Fig. 1B, miR-126 was also downregulated in the TPC-1 and HTH83 cell lines compared with in the NATs $(\mathrm{P}=0.019)$.

miR-126 expression in TPC-1 and HTH83 cell lines post-transfection with miR-126 mimics. To determine the
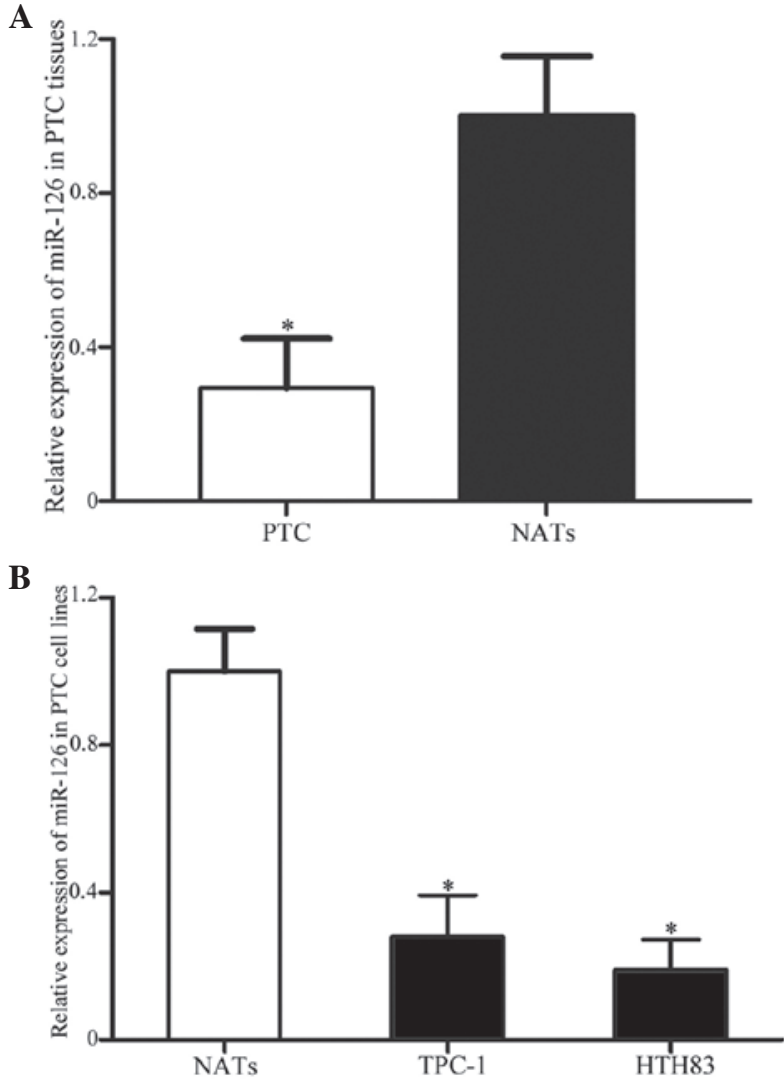

Figure 1. (A) MicroRNA (miR)-126 expression was detected in 20 papillary thyroid carcinoma (PTC) tissues and matched normal adjacent tissues (NATs). miR-126 expression was decreased in human PTC tissues compared with in matched NATs, as determined by quantitative polymerase chain reaction $(\mathrm{P}<0.05)$. (B) miR-126 expression was also downregulated in TPC-1 and HTH83 cell lines compared with in NATs. " $\mathrm{P}<0.05$ ns. NATs. Data are presented as the mean \pm standard deviation.

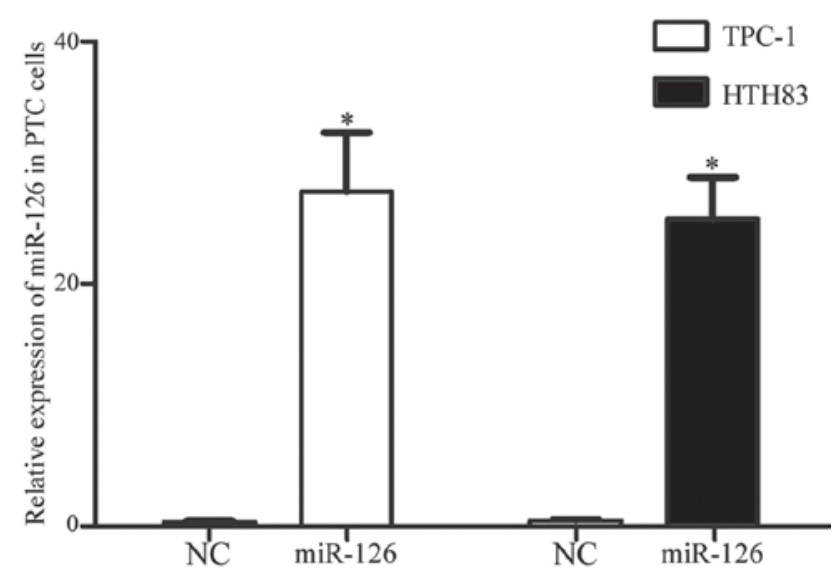

Figure 2. Relative expression of microRNA (miR)-126 post-transfection with miR-126 mimics. Quantitative polymerase chain reaction demonstrated that miR-126 was successfully upregulated in TPC-1 and HTH83 cells post-transfection with miR-126 mimics. " $\mathrm{P}<0.05$ vs. NC. Data are presented as the mean \pm standard deviation. NC, negative control; PTC, papillary thyroid carcinoma.

expression levels of miR-126 in PTC cell lines post-transfection with miR-126 mimics, RT-qPCR was conducted. A total of $120 \mathrm{~h}$ post-transfection, miR-126 expression was significantly upregulated in TPC-1 and HTH83 cell lines (Fig. 2; P=0.001). 

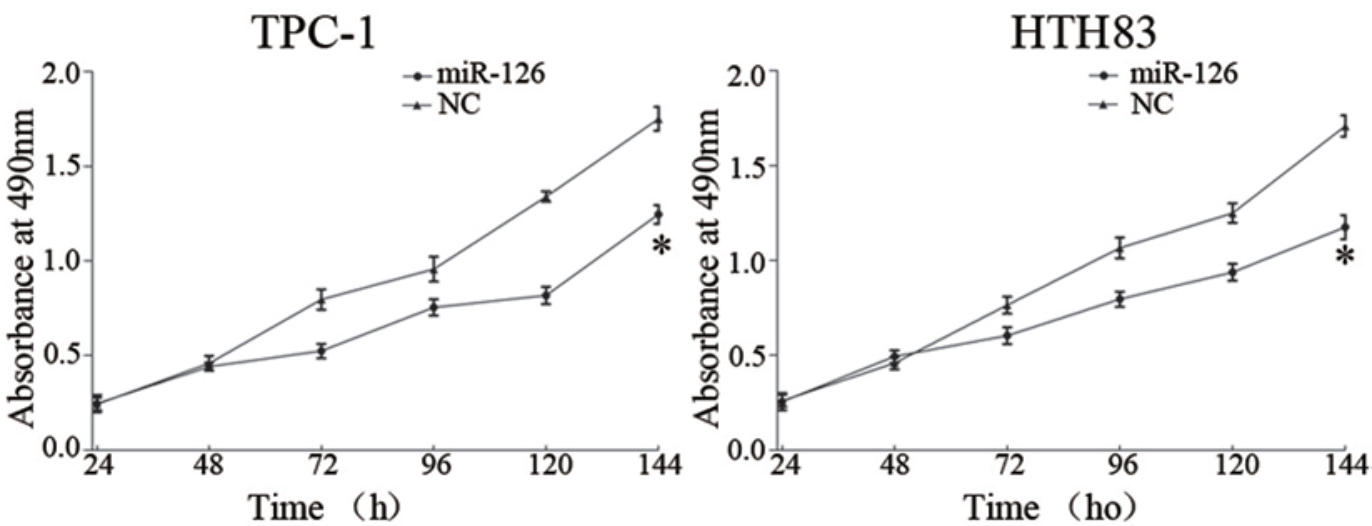

Figure 3. Cell proliferation was determined using a 3-(4,5-dimethyl-2-thiazoyl)-2,5-diphenyl-2H-tetrazolium bromide (MTT) assay. The MTT assay revealed that upregulation of microRNA (miR)-126 significantly suppressed the proliferation of TPC-1 and HTH83 cells ("P<0.05). Data are presented as the mean \pm standard deviation. $\mathrm{NC}$, negative control.
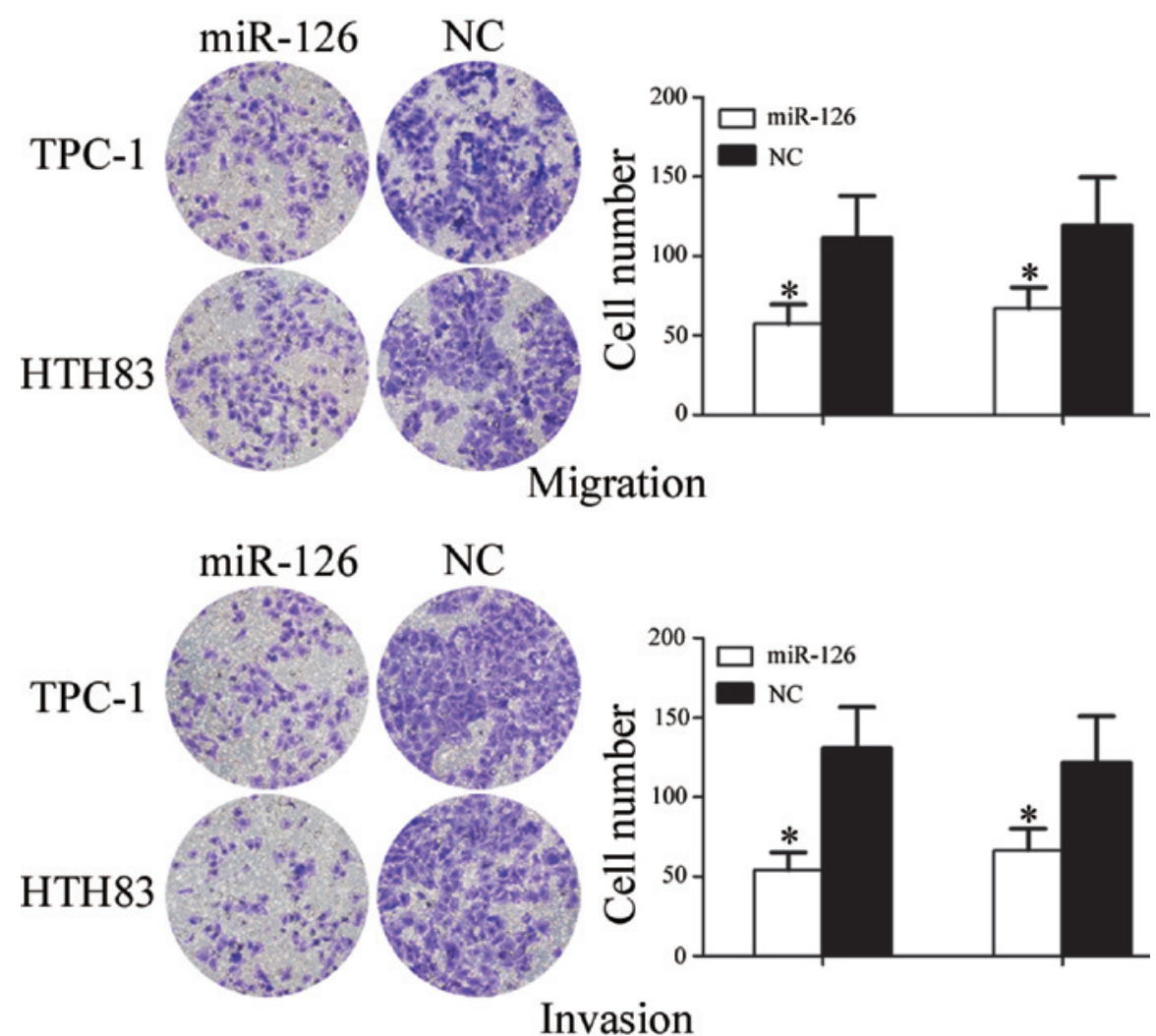

Figure 4. Effects of microRNA (miR)-126 overexpression on TPC-1 and HTH83 migration and invasion. Migration and invasion assays were performed using Transwell chambers. miR-126 overexpression inhibited the migration and invasion of TPC- 1 and HTH 83 cells. ${ }^{*} \mathrm{P}<0.05$ vs. NC. Data are presented as the mean \pm standard deviation. NC, negative control.

miR-126 suppresses proliferation of TPC-1 and HTH83 cells. To verify the effects of miR-126 on cell proliferation, an MTT assay was conducted. As shown in Fig. 3, upregulation of miR-126 significantly inhibited cell proliferation. MTT assays revealed that $144 \mathrm{~h}$ post-transfection, the suppression rate of miR-126 reached $28.91 \pm 4.6 \%$ in TPC- 1 cells $(\mathrm{P}=0.017)$ and $31.43 \pm 3.2 \%$ in HTH83 cells $(\mathrm{P}=0.008)$.

miR-126 inhibits cell migration and invasion of TPC-1 and HTH83 cells. To investigate the role of miR-126 in cell migration, a migration assay was performed. As presented in Fig. 4, the number of migrated TPC-1 and HTH83 cells transfected with miR-126 was significantly downregulated compared with the $\mathrm{NC}$ groups $(\mathrm{P}=0.024$ and $\mathrm{P}=0.039$, respectively).

To investigate the role of miR-126 on cell invasion, an invasion assay was performed. As shown in Fig. 4, the number of invasive TPC-1 and HTH83 cells transfected with miR-126 was significantly downregulated compared with in the NC groups $(\mathrm{P}=0.019$ and $\mathrm{P}=0.032$, respectively). These results indicate that miR-126 may decrease the migration and invasion of TPC-1 and HTH83 cells.

CXCR4 is downregulated post-transfection of TPC-1 and HTH83 cells with miR-126. To identify targets of miR-126, 
A

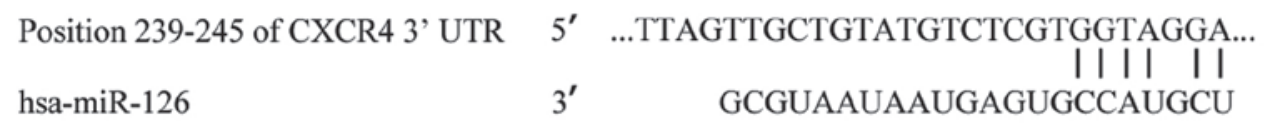

B
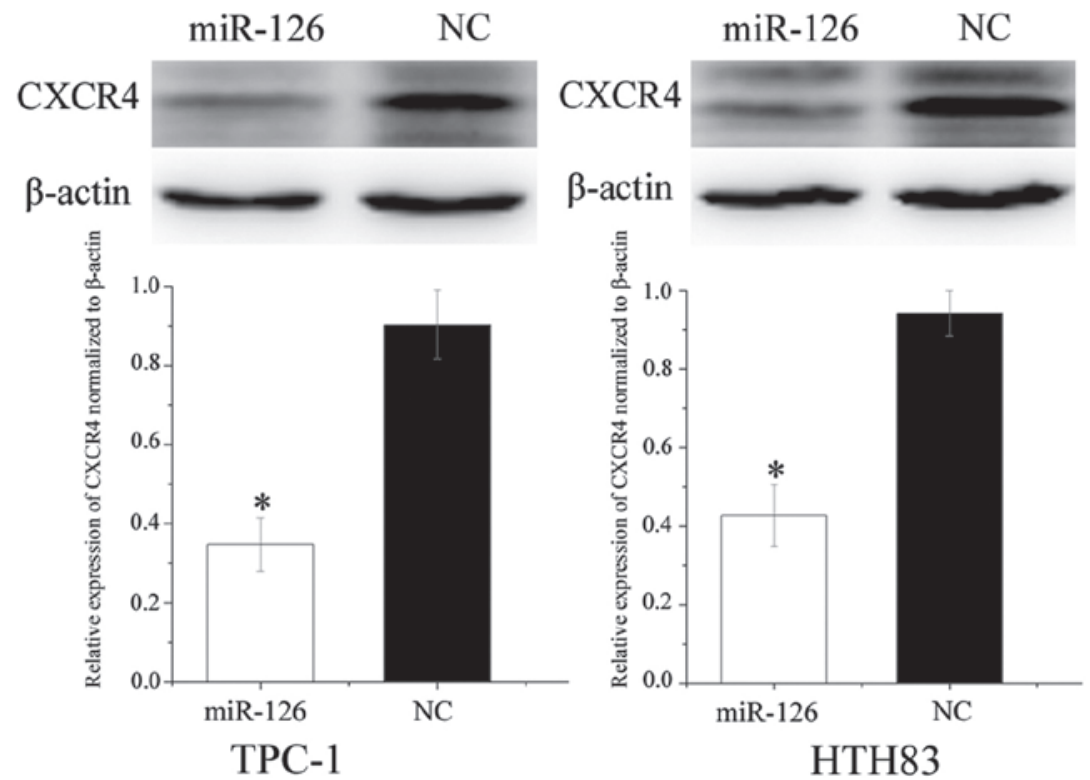

Figure 5. (A) TargetScan predicted that C-X-C chemokine receptor type 4 (CXCR4) mRNA 3'-untranslated region (3'-UTR) contained a microRNA (miR)-126 seed match at position 239-245. (B) Western blotting revealed that CXCR4 was significantly downregulated in TPC-1 and HTH83 cells post-transfection with miR-126. $\mathrm{P}<0.05$ vs. NC. Data are presented as the mean \pm standard deviation. NC, negative control.
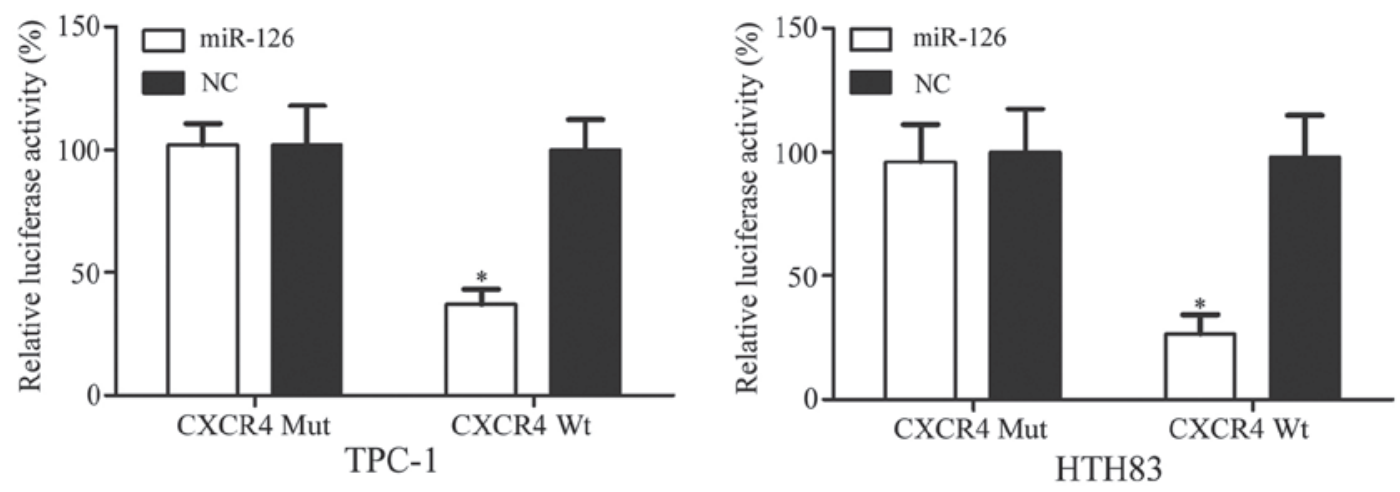

Figure 6. C-X-C chemokine receptor type 4 (CXCR4) was identified as a direct target gene of microRNA (miR)-126. Overexpression of miR-126 significantly inhibited wild-type (Wt) CXCR4, but not mutated (Mut) CXCR4, luciferase activity in TPC-1 and HTH83 cells. "P<0.05 vs. NC. Data are presented as the mean \pm standard deviation. NC, negative control.

TargetScan (http://www.targetscan.org/) was used. CXCR4 was predicted to be a target gene of miR-126 (Fig. 5A). To verify whether miR-126 directly targeted CXCR4, western blotting was performed, in order to determine whether CXCR4 was downregulated post-transfection of TPC-1 and HTH83 cells with miR-126. As presented in Fig. 5B, CXCR4 was significantly downregulated in the TPC-1 and HTH83 cells post-transfection with miR-126 $(\mathrm{P}=0.022$ and $\mathrm{P}=0.036$, respectively).

CXCR4 is a direct target gene of miR-126. Luciferase assays indicated that miR-126 significantly inhibited wild-type CXCR4, but not mutated CXCR4, luciferase activity in TPC-1 $(\mathrm{P}=0.026)$ and HTH83 cells $(\mathrm{P}=0.018$; Fig. 6). These results suggest that CXCR4 is a direct target gene of miR-126 in vitro.

\section{Discussion}

miR-126 is derived from the epidermal growth factor-like domain 7 genes, and is located on chromosome 9q34.3 $(21,22)$. Previous studies have suggested that miR-126 expression differs between normal tissues and tumor tissues $(17,19,23)$. It has been reported to be upregulated in highly vascularized tissues, including the heart, liver and lungs $(24,25)$. However, downregulated miR-126 expression has been detected in various types of cancer, including lung cancer (16), gastric cancer (17), leukemia (18), breast cancer (19), colon 
cancer (26), cervical cancer (27), bladder cancer (28) and prostate cancer (29). To the best of our knowledge, there are no studies regarding the expression of miR-126 in thyroid cancer. The present study demonstrated that miR-126 was significantly downregulated in human thyroid cancer tissues and PTC cell lines, thus suggesting that miR-126 may have an important role in thyroid cancer.

Recently, an increasing number of studies have focused on the function of miR-126 in various types of cancer. In bladder cancer, restoration of miR-126 expression attenuated the invasive potential of bladder cancer cells through its ability to target ADAM metalloproteinase domain 9 (28). In lung cancer, Liu et al (16) reported that miR-126 inhibited cancer cell proliferation and induced cell cycle arrest by directly targeting vascular endothelial growth factor-A. In gastric cancer, Liu et al (17) revealed that miR-126 inhibited cancer cell growth and motility, with Crk as a direct target. In breast cancer, Zhang et al (30) demonstrated that upregulation of miR-126 suppressed cancer cell metastasis and induced cell cycle arrest via the negative regulation of insulin receptor substrate 1 (31). However, to the best of our knowledge, there are no studies regarding the function of miR-126 in thyroid cancer. The present study revealed that miR-126 inhibited thyroid cancer cell proliferation, migration and invasion. These results suggested that miR-126 may be used for the development of novel therapeutic approaches for the treatment of thyroid caner.

Identification of the target genes of miR-126 is essential to improve understanding regarding its role in tumorigenesis, and is important for defining novel therapeutic targets. In the present study, a molecular link between miR-126 and CXCR4 was identified in thyroid cancer. Firstly, TargetScan predicted that CXCR4 was a direct target gene of miR-126. Secondly, as determined by western blotting, upregulation of miR-126 decreased the expression levels of CXCR4 protein in thyroid cancer cell lines. Finally, a luciferase activity assay demonstrated that miR-126 directly targeted CXCR4 3'-UTR, as predicted by TargetScan. These findings suggested that miR-126 may negatively regulate CXCR4 expression in vitro, and may have a tumor-suppressive role in thyroid cancer tumorigenesis and progression.

The processes that induce and stimulate tumor cell migration, invasion and metastasis are very complex, and are modulated by chemokines and their receptors (32). Chemokines are a superfamily of small, structurally related proteins that bind to and interact with G-protein-coupled receptors, resulting in cytoskeletal rearrangement, firm adhesion to endothelial cells and directional migration (33). Chemokine receptors are transmembrane proteins, which interact with chemokine ligands, resulting in G-protein-coupled signal transduction that leads to chemotaxis or directional movement along a chemical gradient (34). CXCR4 is the G-protein-coupled receptor for the chemokine C-X-C motif chemokine ligand 12 (35). CXCR4 is known to be highly expressed in various types of human cancer, and is associated with several biological and pathological processes (36).

High expression of CXCR4 has been detected in various types of tumor, including thyroid cancer (37). CXCR4 expression has also been reported to be correlated with tumor infiltration degree, tumor size, pathological indicators of tumor aggressiveness and lymph node metastasis $(34,38,39)$. In a previous study, knockdown of CXCR4 using a CXCR4-short hairpin RNA interfering vector significantly inhibited thyroid cancer cell proliferation, adhesion and migration (40). These findings suggested that CXCR4 may have an oncogenic role, and may be considered a potentially novel therapeutic target for the suppression of tumor metastasis. The present study demonstrated that miR-126 inhibited CXCR4 expression, in order to regulate thyroid cancer cell migration and invasion. Therefore, miR-126 may be investigated as a predictive value for the early detection of tumor metastasis, and as a therapeutic target for the suppression of thyroid cancer invasion.

In conclusion, the present study demonstrated that miR-126 was downregulated in thyroid cancer. In addition, miR-126 was revealed to inhibit thyroid cancer cell proliferation, migration and invasion by targeting CXCR4. Therefore, miR-126 may be investigated as a target therapy for the suppression of thyroid cancer invasion. Further work is required to address whether the potential of miR-126 may be fully realized in thyroid cancer treatment.

\section{References}

1. Xing M, Haugen BR and Schlumberger M: Progress in molecular-based management of differentiated thyroid cancer. Lancet 381: 1058-1069, 2013.

2. Wang C,Lu S, Jiang J,Jia X, Dong X and Bu P: Hsa-microRNA-101 suppresses migration and invasion by targeting Rac1 in thyroid cancer cells. Oncol Lett 8: 1815-1821, 2014.

3. Zhang X, Li M, Zuo K, Li D, Ye M, Ding L, Cai H, Fu D, Fan Y and Lv Z: Upregulated miR-155 in papillary thyroid carcinoma promotes tumor growth by targeting APC and activating Wnt/ $\beta$-catenin signaling. J Clin Endocrinol Metab 98: E1305-E1313, 2013.

4. Hartmann C, Mueller W and von Deimling A: Pathology and molecular genetics of oligodendroglial tumors. J Mol Med (Berl) 82: 638-655, 2004.

5. Geraldo MV, Fuziwara CS, Friguglieti CU, Costa RB, Kulcsar MA, Yamashita AS and Kimura ET: MicroRNAs miR-146-5p and let-7f as prognostic tools for aggressive papillary thyroid carcinoma: A case report. Arq Bras Endocrinol Metabol 56: 552-557, 2012.

6. Vasko VV and Saji M: Molecular mechanisms involved in differentiated thyroid cancer invasion and metastasis. Curr Opin Oncol 19: 11-17, 2007.

7. Yang Q, Ji M, Guan H, Shi B and Hou P: Shikonin inhibits thyroid cancer cell growth and invasiveness through targeting major signaling pathways. J Clin Endocrinol Metab 98: E1909-E1917, 2013.

8. Zhang X, Li D, Li M, Ye M, Ding L, Cai H, Fu D and Lv Z: MicroRNA-146a targets PRKCE to modulate papillary thyroid tumor development. Int J Cancer 134: 257-267, 2014

9. Lee JC, Gundara JS, Glover A, Serpell J and Sidhu SB: MicroRNA expression profiles in the management of papillary thyroid cancer. Oncologist 19: 1141-1147, 2014.

10. Fabian MR, Sonenberg N and Filipowicz W: Regulation of mRNA translation and stability by microRNAs. Annu Rev Biochem 79: 351-379, 2010.

11. Rigoutsos I: New tricks for animal microRNAs: Targeting of amino acid coding regions at conserved and nonconserved sites. Cancer Res 69: 3245-3248, 2009.

12. Lewis BP, Burge CB and Bartel DP: Conserved seed pairing, often flanked by adenosines, indicates that thousands of human genes are microRNA targets. Cell 120: 15-20, 2005.

13. Li D, Jian W, Wei C, Song H, Gu Y, Luo Y and Fang L: Down-regulation of miR-181b promotes apoptosis by targeting CYLD in thyroid papillary cancer. Int J Clin Exp Pathol 7: 7672-7680, 2014.

14. Wu D, Zhou Y, Pan H, Qu P and Zhou J: MicroRNA99a inhibits cell proliferation, colony formation ability, migration and invasion by targeting fibroblast growth factor receptor 3 in prostate cancer. Mol Med Rep 11: 1469-1475, 2015. 
15. Pallante P, Battista S, Pierantoni GM and Fusco A: Deregulation of microRNA expression in thyroid neoplasias. Nat Rev Endocrinol 10: 88-101, 2014.

16. Liu B, Peng XC, Zheng XL, Wang J and Qin YW: MiR-126 restoration down-regulate VEGF and inhibit the growth of lung cancer cell lines in vitro and in vivo. Lung Cancer 66: 169-175, 2009.

17. Liu LY, Wang W, Zhao LY, Guo B, Yang J, Zhao XG, Hou N, Ni L, Wang AY, Song TS, et al: Mir-126 inhibits growth of SGC-7901 cells by synergistically targeting the oncogenes PI3KR 2 and Crk, and the tumor suppressor PLK2. Int J Oncol 45: 1257-1265, 2014

18. Akbari Moqadam F, Boer JM, Lange-Turenhout EA, Pieters R and den Boer ML: Altered expression of miR-24, miR-126 and miR-365 does not affect viability of childhood TCF3-rearranged leukemia cells. Leukemia 28: 1008-1014, 2014

19. Zhu N, Zhang D, Xie H, Zhou Z, Chen H, Hu T, Bai Y, Shen Y, Yuan W, Jing Q and Qin Y: Endothelial-specific intron-derived miR-126 is down-regulated in human breast cancer and targets both VEGFA and PIK3R2. Mol Cell Biochem 351: 157-164, 2011

20. Livak KJ and Schmittgen TD: Analysis of relative gene expression data using real-time quantitative PCR and the 2(-Delta Delta C(T)) Method. Methods 25: 402-408, 2001.

21. Fish JE, Santoro MM, Morton SU, Yu S, Yeh RF, Wythe JD, Ivey KN, Bruneau BG, Stainier DY and Srivastava D: MiR-126 regulates angiogenic signaling and vascular integrity. Dev Cell 15: 272-284, 2008.

22. Saito Y, Friedman JM, Chihara Y, Egger G, Chuang JC and Liang G: Epigenetic therapy upregulates the tumor suppressor microRNA-126 and its host gene EGFL7 in human cancer cells. Biochem Biophys Res Commun 379: 726-731, 2009.

23. Feng R, Chen X, Yu Y, Su L, Yu B, Li J, Cai Q, Yan M, Liu B and Zhu Z: MiR-126 functions as a tumour suppressor in human gastric cancer. Cancer Lett 298: 50-63, 2010.

24. Lagos-Quintana M, Rauhut R, Yalcin A, Meyer J, Lendeckel W and Tuschl T: Identification of tissue-specific microRNAs from mouse. Curr Biol 12: 735-739, 2002.

25. Meister J and Schmidt MH: MiR-126 and miR-126*: New players in cancer. ScientificWorldJournal 10: 2090-2100, 2010.

26. Li N, Tang A, Huang S, Li Z, Li X, Shen S, Ma J and Wang X MiR-126 suppresses colon cancer cell proliferation and invasion via inhibiting RhoA/ROCK signaling pathway. Mol Cell Biochem 380: 107-119, 2013.

27. Yu Q, Liu SL, Wang H, Shi G, Yang P and Chen XL: MiR-126 suppresses the proliferation of cervical cancer cells and alters cell sensitivity to the chemotherapeutic drug bleomycin. Asian Pac J Cancer Prev 14: 6569-6572, 2014

28. Jia AY, Castillo-Martin M, Bonal DM, Sánchez-Carbayo M, Silva JM and Cordon-Cardo C: MicroRNA-126 inhibits invasion in bladder cancer via regulation of ADAM9. Br J Cancer 110: 2945-2954, 2014
29. Sun X, Liu Z, Yang Z, Xiao L, Wang F, He Y, Su P, Wang J and Jing B: Association of microRNA-126 expression with clinicopathological features and the risk of biochemical recurrence in prostate cancer patients undergoing radical prostatectomy. Diagn Pathol 8: 208, 2013.

30. Zhang J, Du YY, Lin YF, Chen YT, Yang L, Wang HJ and Ma D: The cell growth suppressor, mir-126, targets IRS-1. Biochem Biophys Res Commun 377: 136-140, 2008.

31. Zhang Y, Yang P, Sun T, Li D, Xu X, Rui Y, Li C, Chong M, Ibrahim T, Mercatali L, et al: MiR-126 and miR-126* repress recruitment of mesenchymal stem cells and inflammatory monocytes to inhibit breast cancer metastasis. Nat Cell Biol 15: 284-294, 2013

32. Yarden Y: The EGFR family and its ligands in human cancer. signalling mechanisms and therapeutic opportunities. Eur J Cancer 37 (Suppl 4): S3-S8, 2001.

33. Balkwill FR: The chemokine system and cancer. J Pathol 226: 148-157, 2012.

34. Wang N, Luo HJ, Yin GB, Dong CR, Xu M, Chen GG and Liu ZM: Overexpression of HIF-2 $\alpha$, TWIST, and CXCR4 is associated with lymph node metastasis in papillary thyroid carcinoma. Clin Dev Immunol 2013: 589423, 2013.

35. Oberlin E, Amara A, Bachelerie F, Bessia C, Virelizier JL, Arenzana-Seisdedos F, Schwartz O, Heard JM, Clark-Lewis I, Legler DF, et al: The CXC chemokine SDF-1 is the ligand for LESTR/fusin and prevents infection by T-cell-line-adapted HIV-1. Nature 382: 833-835, 1996

36. He X, Wei Q, Zhang X, Xiao J, Jin X, Zhu Y, Cui B and Ning G: Immunohistochemical expression of CXCR4 in thyroid carcinomas and thyroid benign lesions. Pathol Res Pract 206: 712-715, 2010.

37. Castellone MD, Guarino V, De Falco V, Carlomagno F, Basolo F, Faviana P, Kruhoffer M, Orntoft T, Russell JP, Rothstein JL, et al: Functional expression of the CXCR4 chemokine receptor is induced by RET/PTC oncogenes and is a common event in human papillary thyroid carcinomas. Oncogene 23: 5958-5967, 2004.

38. Torregrossa L, Giannini R, Borrelli N, Sensi E, Melillo RM, Leocata P, Materazzi G, Miccoli P, Santoro M and Basolo F: CXCR4 expression correlates with the degree of tumor infiltration and BRAF status in papillary thyroid carcinomas. Mod Pathol 25: 46-55, 2012.

39. Wagner PL, Moo TA, Arora N, Liu YF, Zarnegar R, Scognamiglio T and Fahey TJ III: The chemokine receptors CXCR4 and CCR7 are associated with tumor size and pathologic indicators of tumor aggressiveness in papillary thyroid carcinoma. Ann Surg Oncol 15: 2833-2841, 2008.

40. Guo S, Xiao D, Liu H, Zheng X, Liu L and Liu S: Interfering with CXCR4 expression inhibits proliferation, adhesion and migration of breast cancer MDA-MB-231 cells. Oncol Lett 8: 1557-1562, 2014. 